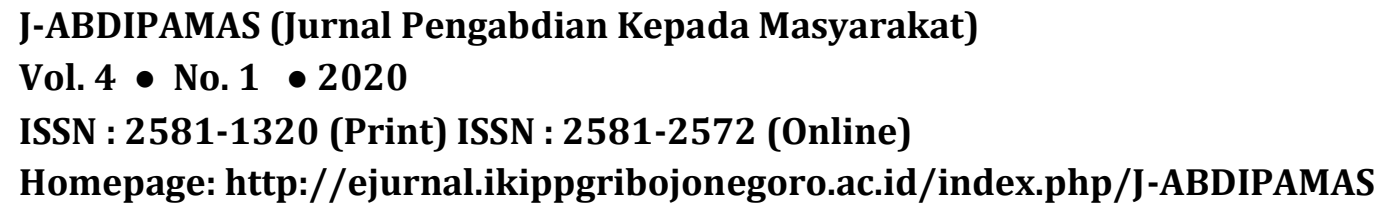

ISSN : 2581-1320 (Print) ISSN : 2581-2572 (Online)

Homepage: http://ejurnal.ikippgribojonegoro.ac.id/index.php/J-ABDIPAMAS

\title{
PELATIHAN PEMANFAATAN CLOUD STORAGE DAN WEBLOG BAGI SMAN 11 PULAU BULUH
}

\author{
Cosmas Eko Suharyanto ${ }^{1}$, Alfannisa Annurrullah Fajrin ${ }^{2}$ \\ ${ }^{1}$ Universitas Putera Batam. Email: cosmas@putrabatam.ac.id \\ 2Universitas Putera Batam. Email: asykharit1302@gmail.com
}

\begin{abstract}
Technology has changed the way people communicate, interact and act in various tasks and activities. One of them is how people store digital data in a storage medium. Conventional storage media such as hard disks, flash disks, CD / DVDs have begun to be abandoned. One reason has begun to be abandoned is that important data is often lost along with the loss of the media. Technology, especially the internet, has become one of the solutions in the world of storage media, namely the presence of cloud technology through cloud storage. In addition to being the answer, the internet is also a means of communication through weblog media or often abbreviated as blogs. Almost the same as Cloud Computing technology, Weblog is a blog collaboration tool so that not only a user can do blogging activities, but is done together, from anywhere and at any time. Weblogs can be an effective media of information about an organization's activities. These two things are the background of the plan of Community Service activities at SMAN 11 Buluh Island Batam. For teachers, cloud storage technology has been introduced through lectures and hands-on training, while for the student council management has been trained on how to design a weblog in accordance with the needs of the school, especially the students. Teachers can take advantage of the benefits of cloud storage for various purposes. The management of OSIS SMAN 11 Buluh Islah Batam can have a means of communication and creativity event with webloging activities.
\end{abstract}

Keywords: Weblog, Cloud Computing, Cloud Storage

\begin{abstract}
ABSTRAK
Teknologi telah merubah cara orang berkomunikasi, berinteraksi dan beraksi dalam berbagai tugas dan aktivitasnya. Salah satunya bagaimana orang menyimpan data-data digital dalam sebuah media penyimpanan. Media penyimpanan konvensional seperti hard disk, flash disk, CD/DVD telah mulai ditinggalkan. Salah satu alasan sudah mulai ditinggalkan yaitu data penting sering hilang bersamaan dengan hilangnya media tersebut. Teknologi khususnya internet telah menjadi salah satu solusi dalam dunia media storage yaitu hadirnya teknologi cloud melalui cloud storage. Selain menjadi jawaban tersebut, internet juga menjadi sarana komunikasi melalui media weblog atau sering disingkat dengan blog. Hampir sama seperti teknologi Cloud Computing, Weblog adalah sarana kolaborasi blog agar tidak hanya seorang user saja yang dapat melakukan aktivitas blogging, namun dikerjakan secara bersama-sama, dari mana saja dan kapan saja. Weblog dapat menjadi media informasi yang efektif tentang suatu kegiatan organisasi. Kedua hal tersebut yang melatar belakangi rencana kegiatan Pengabdian kepada Masyarakat di SMAN 11 Pulau Buluh Batam. Bagi para guru telah diperkenalkan teknologi cloud storage melalui ceramah dan pelatihan langsung, sedangkan bagi pengurus OSIS telah dilatih bagaimana mendesain sebuah weblog sesuai dengan kebutuhan sekolah khususnya para siswa-siswinya. Para guru dapat memanfaatkan berbagai keunggulan pengimpanan awan untuk berbagai keperluan. Pengurus OSIS SMAN 11 Pulau Buluh Batam dapat memiliki sarana komunikasi dan ajang kreatifitas dengan aktivitas webloging.
\end{abstract}

Kata Kunci: Weblog, Cloud Computing, Cloud Storage 


\section{PENDAHULUAN}

Cloud Computing merupakan gabungan pemanfaatan teknologi komputer dan pengembangan berbasis Internet atau sering disebut "awan". Awan (cloud) adalah metafora dari internet, sebagaimana awan yang sering digambarkan di diagram jaringan komputer. Sebagaimana awan dalam diagram jaringan komputer tersebut, awan (cloud) dalam Cloud Computing juga merupakan abstraksi dari infrastruktur kompleks yang disembunyikannya. Ia adalah suatu mode komputasi di mana kapabilitas terkait teknologi informasi disajikan sebagai suatu layanan, sehingga pengguna dapat mengaksesnya lewat Internet tanpa pengetahuan tentangnya, ahli dengannya, atau memiliki kendali terhadap infrastruktur teknologi yang membantunya (Sultan, 2010). Cloud storage masuk ke dalam teknologi cloud computing ini. Bedanya terletak pada penggunaan teknologi di mana cloud computing bukan hanya menyimpan tetapi kita juga bisa mengakses data untuk mengolahnya menggunakan aplikasi yang berada di awan.

Cloud Storage sebagai penyimpanan data digital yang memanfaatkan adanya server virtual sebagai media penyimpanan(Goda \& Kitsuregawa, 2012). Tidak seperti media penyimpanan perangkat keras pada umumnya seperti CD atau hard disk, teknologi Cloud Storage tidak membutuhkan perangkat tambahan apapun. Hal yang kita perlukan untuk mengakses file digital hanyalah perangkat komputer atau gadget yang telah dilengkapi layanan internet. Dengan mengadopsi penggunaan internet sebagai media simpannya, teknologi Cloud Storage nyatanya mempunyai banyak sekali keunggulan jika dibandingkan dengan media penyimpanan perangkat keras seperti CD, hard disk, portable disk atau bentuk yang lain.Beberapa keunggulan Cloud Storage diantaranya mengenai sisi skalabilitas, maksudnya adalah penggunaan Cloud Storage dapat disesuaikan dengan kebutuhan dari pengguna itu sendiri. Dengan penambahan perangkat keras, sebuah penyedia layanan Cloud Storage bisa meningkatkan daya tampung datanya. Bagi para pengguna tentunya menjadi pilihan yang lebih baik dan efektif dengan menyesuaikan kapasitas Cloud Storage yang diperlukan. Keunggulan berikutnya adalah aksesibiltas, maksudnya adalah kemudahan ketika anda ingin menggunakan layanan tersebut. Dengan adanya teknologi Cloud Storage, anda bisa dengan mudah mengunduh, membuka atau melakukan editing terhadap data yang telah tersimpan kapanpun dan dimanapun selama perangkat kita masih terkoneksi internet. Hal ini menjadi opsi yang sangat penting bagi para pengguna layanan Cloud Storage terutama bagi perusahaan yang membutuhkan bisa mengakses data yang diperlukan dengan lebih mudah dan cepat. Keuntungan lain dari teknologi Cloud Storage adalah masalah keamanan. Hal ini menjadi salah satu faktor yang paling penting karena para pengguna tentunya mengharapkan data yang tersimpan di Cloud Storage dapat terjaga keamanannya. Tidak hanya itu dengan menyimpan data digitalnya pada Cloud Storage akan mengurangi resiko kehilangan data jika terjadi masalah pada perangkat elektronik kita. Kejadian hilangnya data akibat kerusakan perangkat seperti komputer, laptop atau gadget lain pun bisa teratasi dengan adanya teknologi penyimpanan tersebut. 
Hampir sama seperti teknologi Cloud Computing, Weblog adalah sarana kolaborasi blog agar tidak hanya seorang user saja yang dapat melakukan aktivitas blogging, namun dikerjakan secara bersama-sama, dari mana saja dan kapan saja. Secara umum, Weblog merupakan catatan pribadi sesorang di internet, yang berisi informasi yang sering di update dan kronologis (Kurose \& Ross, 2013). Banyak Weblog yang fokus terhadap satu objek informasi, misalnya politik, web design, olah raga dll. Tetapi ada juga yang lebih seperti jurnal pribadi yang berisi informasi perjalanan dan kehidupan sehari-hari seseorang bloger dan pemikirannya.

Manfaat Weblog sangat banyak, tergantung dari segi mana dan oleh siapa Weblog itu dipandang. Dalam dunia pendidikan pemanfaatan media blog dapat meningkatan kualitas diri dan kompetensi seorang guru ataupun siswa (Noytim, 2010). Dengan kekuatan yang dimiliki Weblog, seorang guru dapat menuliskan apapun tentang kegiatan di sekolah seperti menceritakan kegiatan belajar yang menyenangkan bersama murid-murid, menceritakan inovasi dalam metode mengajar yang memang menarik minat dan bisa jadi contoh bagi guru-guru yang lain untuk dipraktekkan di kelas mereka, menuliskan berbagai keluhan mengenai kebijakan sekolah. Weblog bisa menjadi cermin evaluasi diri karena tulisan-tulisan juga dikomentari oleh banyak orang dengan berbagai sudut pandang, sehingga kita juga belajar memahami berbagai karakter orang dan sudut pandang seseorang menyikapi masalah. Selain itu dengan memanfaatan media blog memungkinkan seorang guru untuk bertukar pikiran dengan guru lain di manapun, sharing kiat mengajar, bahan ajar dan sebaginya yang semuanya memperlancar kegiatan belajar mengajar dalam rangka peningkatan kompetensi guru dan pendidikan pada umumnya. Bagi siswa sarana Weblog dapat dimanfaatkan sebagai catatan atas tugas-tugas sekolah, melatih kemampuan menulis maupun share tugas dengan siswa lainnya (Ùimúek, 2010).

\section{METODE PELAKSANAAN}

Dalam melakukan pengabdian ini, kami menggunakan beberapa metode agar proses pengabdian dapat berjalan dengan baik, terutama tujuan pengabdian dapat tercapai.

Tabel 1. Metode Pelaksanaan

\begin{tabular}{lll}
\hline No & Solusi yang ditawarkan & \multicolumn{1}{c}{ Metode yang digunakan } \\
\hline 1 & Pemanfaatan Cloud & - Ceramah dan Diskusi tentang apa itu Cloud Storage \\
& Storage sebagai media & dan manfaatnya \\
& penyimpanan data & - Workshop instalasi dan penggunaan Cloud Storage \\
& & sebagai media penyimpanan data digital \\
\hline 2 & Pembuatan Weblog OSIS & - Ceramah dan diskusi tentang weblog dan manfaat \\
& SMAN 11 Pulau Buluh & weblog \\
& & - Workshop pembuatan weblog dan pengisian konten \\
& & weblog \\
\hline
\end{tabular}

Salah satu indikator yang baik bagi kegiatan pengabdian kepada masyarakat adalah adanya hubungan yang baik paska kegiatan. Selain terkait tema yang diabdi juga 
hubungan dengan objek pengabdian. Terkait dengan tema pengabdian, kami merencanakan akan terus memantau weblog OSIS juga jika memungkinkan untuk mengunjungi lagi. Sedangkan terkait dengan objek yang diabdi, kami akan merekomendasikan tim lain agar juga melakukan di tempat tersebut degan tema yang berbeda.

Setiap kegiatan selain memiliki tujuan yang akan dicapai juga harus dievaluasi bagaimana proses pencapaian tujuan tersebut. Evaluasi dilakukan agar kekurangan dari pengabdian yang telah dilakukan dapat diperbaiki pada pengabdian selanjutnya.

Tabel 2 Evaluasi Pelaksanaan Kegiatan

\begin{tabular}{|c|c|c|}
\hline Evaluasi & Indikator/ Tujuan & Evaluasi \\
\hline Evaluasi tim & 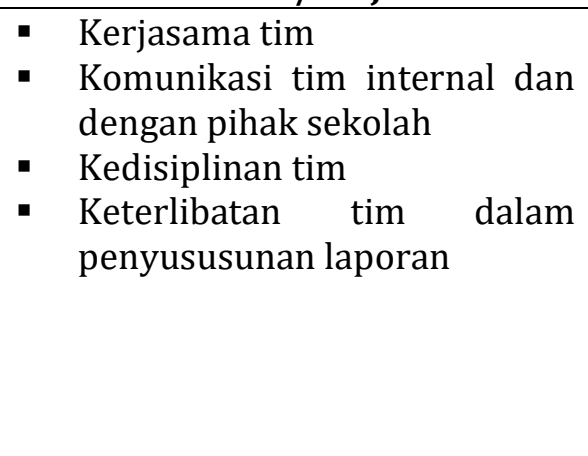 & 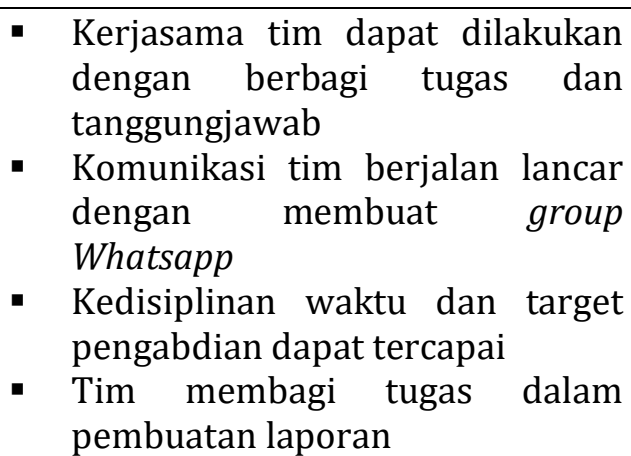 \\
\hline $\begin{array}{l}\text { Evaluasi } \\
\text { Pemanfaat } \\
\text { Cloud Storage }\end{array}$ & $\begin{array}{l}\text { - Semua guru terlibat dan aktif } \\
\text { dalam proses pengabdian } \\
\text { - Semua guru memiliki akun } \\
\text { Cloud Storage } \\
\text { - Semua guru memanfaatkan } \\
\text { Cloud Storage }\end{array}$ & $\begin{array}{l}\text { - Para guru aktif mengikuti setiap } \\
\text { langkah dalam pelatihan } \\
\text { - Masih ada beberapa guru yang } \\
\text { tidak ikut pelatihan karena tugas } \\
\text { keluar } \\
\text { - Masih ada beberapa guru yang } \\
\text { tidak dapat memanfaatkan } \\
\text { karena tidak ikut pelatihan, } \\
\text { karena tugas keluar }\end{array}$ \\
\hline $\begin{array}{l}\text { Evaluasi } \\
\text { Weblog OSIS } \\
\text { SMAN } 11 \text { Pulau } \\
\text { Buluh }\end{array}$ & 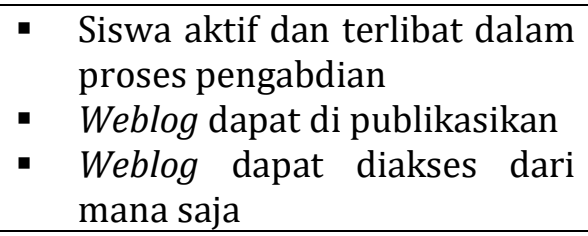 & $\begin{array}{l}\text { - Siswa/ pengurus OSIS terlibat } \\
\text { aktif } \\
\text { - Tercapai sebagaimana dijelaskan } \\
\text { di bab IV } \\
\text { - Tercapai }\end{array}$ \\
\hline
\end{tabular}

\section{HASIL DAN PEMBAHASAN}

Pelatihan ini ditujukan untuk para pengurus OSIS SMAN 11 Pulau Buluh Batam. Pelatihan pembuatan Weblog untuk OSIS SMAN 11 Batam dilakukan selama dua hari, tanggal 3-4 Januari 2018.

Setelah diadakan pelatihan ini, para pengurus OSIS SMAN 11 Pulau Buluh Batam dapat mengetahui apa manfaat dari weblog, OSIS SMAN 11 Pulau Buluh Batam telah memiliki media komunikasi weblog dengan tautan sebagai berikut: https://osis11batam.wordpress.com/. Selain itu, anggota OSIS SMAN 11 Pulau Buluh 
Batam dapat merancang, membuat dan mengisi weblog dengan baik. Anggota OSIS SMAN 11 Pulau Buluh Batam bekerjasama dapat mengelola weblog yang telah dibuat.

Pertama, terkait pembahasan pelatihan weblog. Rancangan weblog kami menggunakan media blog Wordpress. Alasan kami memilih Wordpress karena dapat di desain dalam keadaan offline. Wordpress dikategorikan sebagai Content Management System (CMS) yang user friendly.

Berikut penjelasan tahap demi tahap pelatihan weblog:

Tabel 3. Tahap Pelatihan Weblog

\begin{tabular}{|c|c|}
\hline AKTIVITAS & KETERANGAN \\
\hline Persiapan & $\begin{array}{l}\text { pada tahap ini kami memastikan laptop yang digunakan siswa sudah siap } \\
\text { dan terhubung dengan internet }\end{array}$ \\
\hline Ceramah & pada tahap ini tim memberikan materi teori terkait dunia weblog \\
\hline $\begin{array}{l}\text { Pengenalan } \\
\text { Wordpress }\end{array}$ & $\begin{array}{l}\text { pada tahap ini tim secara khusus memperkenalkan tool yang akan } \\
\text { digunakan dalam proses perancangan weblog }\end{array}$ \\
\hline $\begin{array}{l}\text { Praktek } \\
\text { membuat } \\
\text { weblog }\end{array}$ & $\begin{array}{l}\text { pada tahap ini tim memandu siswa untuk membuat weblog mulai dari } \\
\text { pembuatan akun sampai proses posting artikel }\end{array}$ \\
\hline $\begin{array}{l}\text { Desain weblog } \\
\text { OSIS SMAN } 11 \\
\text { Pulau Buluh } \\
\text { Batam }\end{array}$ & $\begin{array}{l}\text { pada tahap ini tim secara khusus mengarahkan semua siswa untuk } \\
\text { merancang weblog OSIS dengan cara share akun, agar semua dapat } \\
\text { melakukan proses penyuntingan. Struktur weblog dapat dilihat dalam Tabel } \\
5 \text { dibawah. }\end{array}$ \\
\hline $\begin{array}{l}\text { Pembagian } \\
\text { tugas artikel }\end{array}$ & $\begin{array}{l}\text { pada tahap ini tim membagi kelompok-kelompok kecil dan setiap kelompok } \\
\text { bertugas membuat suatu artikel yang akan nantinya dimuat dalam weblog }\end{array}$ \\
\hline Posting artikel & $\begin{array}{l}\text { setelah artikel selesai maka tim mengarahkan agar artikel dapat } \\
\text { dipublikasikan atau di posting sesuai dengan kategori artikel }\end{array}$ \\
\hline $\begin{array}{l}\text { Update } \\
\text { homepage }\end{array}$ & pada tahap ini dilakukan desain layout dari template asli agar lebih menarik \\
\hline Finishing & $\begin{array}{l}\text { ni adalah memeriksa semua tautan dan berkas dan proses } \\
\text { blog. }\end{array}$ \\
\hline
\end{tabular}

Kedua, adalah pelatihan pemanfaatan media penyimpanan awan (cloud storage) bagi para guru SMAN 11 Pulau Buluh Batam. Pelatihan ini dapat diselesaikan dengan baik dengan proses sebagai berikut:

Tabel 4. Tahap Pelatihan Cloud Storage

AKTIVITAS

Ceramah materi pada tahap ini dijelaskan berbagai manfaat media penyimpanan awan, penjelasan berbagai macam produk penyedia layanan penyimpanan awan dengan berbagai kelemahan dan keunggulannya.

Akun Google $\quad$ pada tahap ini dimulai dengan pembuatan akun Google. Akun Google inilah nanti yang akan digunakan untuk memanfaatkan layanan media penyimpanan awan google yaitu Google drive.

Instalasi Google tahap ini adalah instalasi aplikasi Google Drive Dekstop agar dapat Drive Dekstop Menyimpan berkas Sinkronisasi terintegrasi dengan manajemen berkas pada perangkat laptop. tahap ini adalah melakukan uji coba menyimpan berkas di folder Google drive yang sudah terinstal di laptop pada tahap ini para guru membuka akun Google drive-nya melalui 
perangkat lain, yaitu smartphone.

Berbagi berkas salah satu keunggulan media penyimpanan awan adalah pengguna dapat melakukan share pekerjaan/ proyek sehingga beberapa pengguna dapat melakukan proses penyuntingan secara simultan. Pada tahap ini peserta diminta untuk melakukan share file ke pengguna lain dan melakukan proses editing bersama.

Penutup dan $\quad$ sesi ini kami melakukan sesi tanya jawab, dan ditutup oleh perwakilan guru. tanya jawab Pada sesi ini juga diisi dengan pemanfaatan aplikasi file recovery untuk membantu para guru apabila mengalami kehilangan data sehingga dapat di retrieve kembali. Aplikasi yang tim pengabdi berikan adalah "Recuva", karena sangat user friendly.

Seluruh kegiatan secara teknis menyesuaikan dengan kondisi lapangan dan permintaan objek pengabdian. Berikut hasil dari tampilan Weblog untuk SMAN 11 Pulau Buluh Batam:

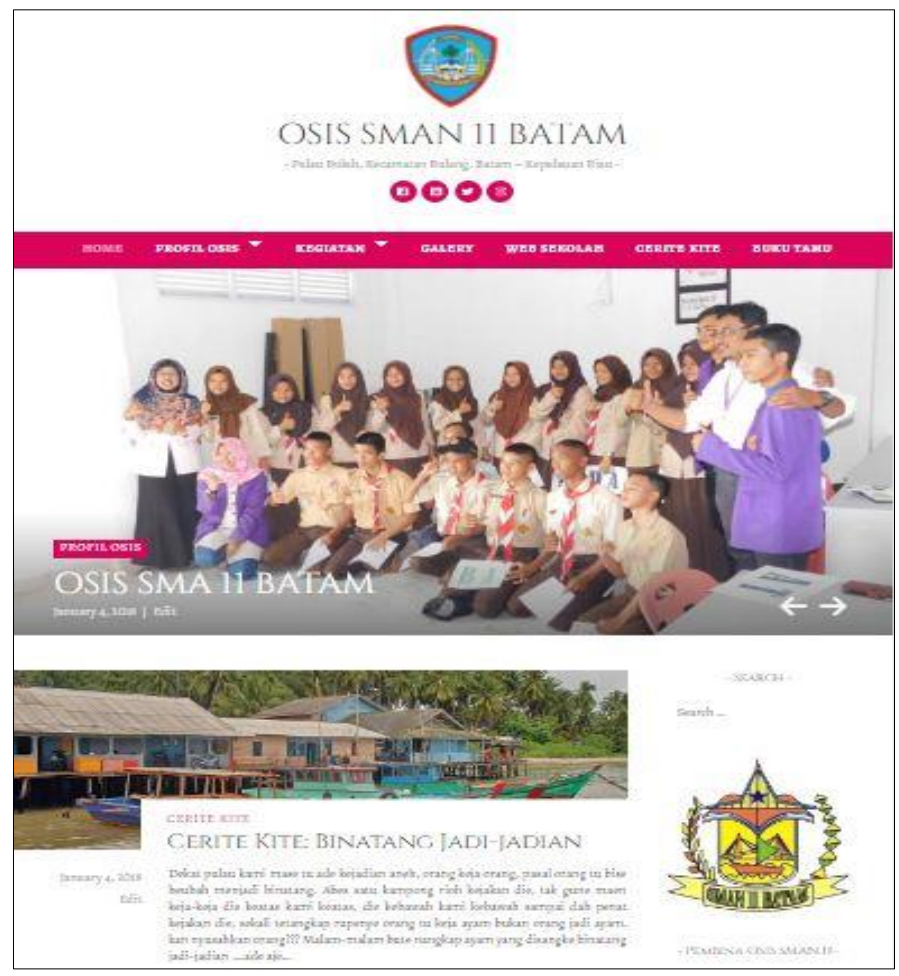

Gambar 1 Tampilan weblog OSIS SMAN 11 Batam

Tabel 5. Struktur Weblog OSIS SMAN 11 Batam

\begin{tabular}{|c|c|c|c|c|c|c|}
\hline \multicolumn{7}{|c|}{ MENU } \\
\hline HOME & PROFIL OSIS & KEGIATAN & GALERY & $\begin{array}{l}\text { WEBSITE } \\
\text { SEKOLAH }\end{array}$ & $\begin{array}{l}\text { CERITE } \\
\text { KITE }\end{array}$ & $\begin{array}{l}\text { BUKU } \\
\text { TAMU }\end{array}$ \\
\hline $\begin{array}{l}\text { https://osis } \\
11 \text { batam.w } \\
\text { ordpress.co } \\
\text { m/ } \\
\text { Ini adalah } \\
\text { menu } \\
\text { "Beranda" }\end{array}$ & $\begin{array}{l}\text { - SELAMAT } \\
\text { DATANG } \\
\text { - STRUKTUR } \\
\text { ORGANISASI } \\
\text { OSIS SMAN } 11 \\
\text { BATAM } \\
\text { - LOGO OSIS } \\
\text { - PROFIL } \\
\text { SEKOLAH } \\
\text { - CONTACT US }\end{array}$ & $\begin{array}{ll}- & \text { KEGIATAN } \\
& \text { TAHUN } \\
& 2017 \\
- & \text { KEGIATAN } \\
& \text { TAHUN } \\
& 2018\end{array}$ & $\begin{array}{l}\text { Berisikan } \\
\text { semua } \\
\text { posting } \\
\text { dengan } \\
\text { kategori } \\
\text { "gallery" }\end{array}$ & $\begin{array}{l}\text { Berisikan } \\
\text { tautan } \\
\text { statis } \\
\text { http://ww } \\
\text { w.sman11b } \\
\text { atam.sch.id } \\
\text { / }\end{array}$ & $\begin{array}{l}\text { Berisikan } \\
\text { semua } \\
\text { posting } \\
\text { dengan } \\
\text { kategori } \\
\text { "cerite kite", } \\
\text { yaitu berupa } \\
\text { cerita khas } \\
\text { dari Pulau } \\
\text { Buluh }\end{array}$ & $\begin{array}{l}\text { Berisikan } \\
\text { form, } \\
\text { sehingga } \\
\text { pengunju } \\
\text { ng dapat } \\
\text { saling } \\
\text { sapa }\end{array}$ \\
\hline
\end{tabular}


Salah satu indikator yang baik bagi kegiatan pengabdian kepada masyarakat adalah adanya hubungan yang baik paska kegiatan. Selain terkait tema yang diabdi juga hubungan dengan objek pengabdian. Terkait dengan tema pengabdian, kami merencanakan akan terus memantau weblog OSIS juga jika memungkinkan untuk mengunjungi lagi. Sedangkan terkait dengan objek yang diabdi, kami akan merekomendasikan tim lain agar juga melakukan di tempat tersebut degan tema yang berbeda.

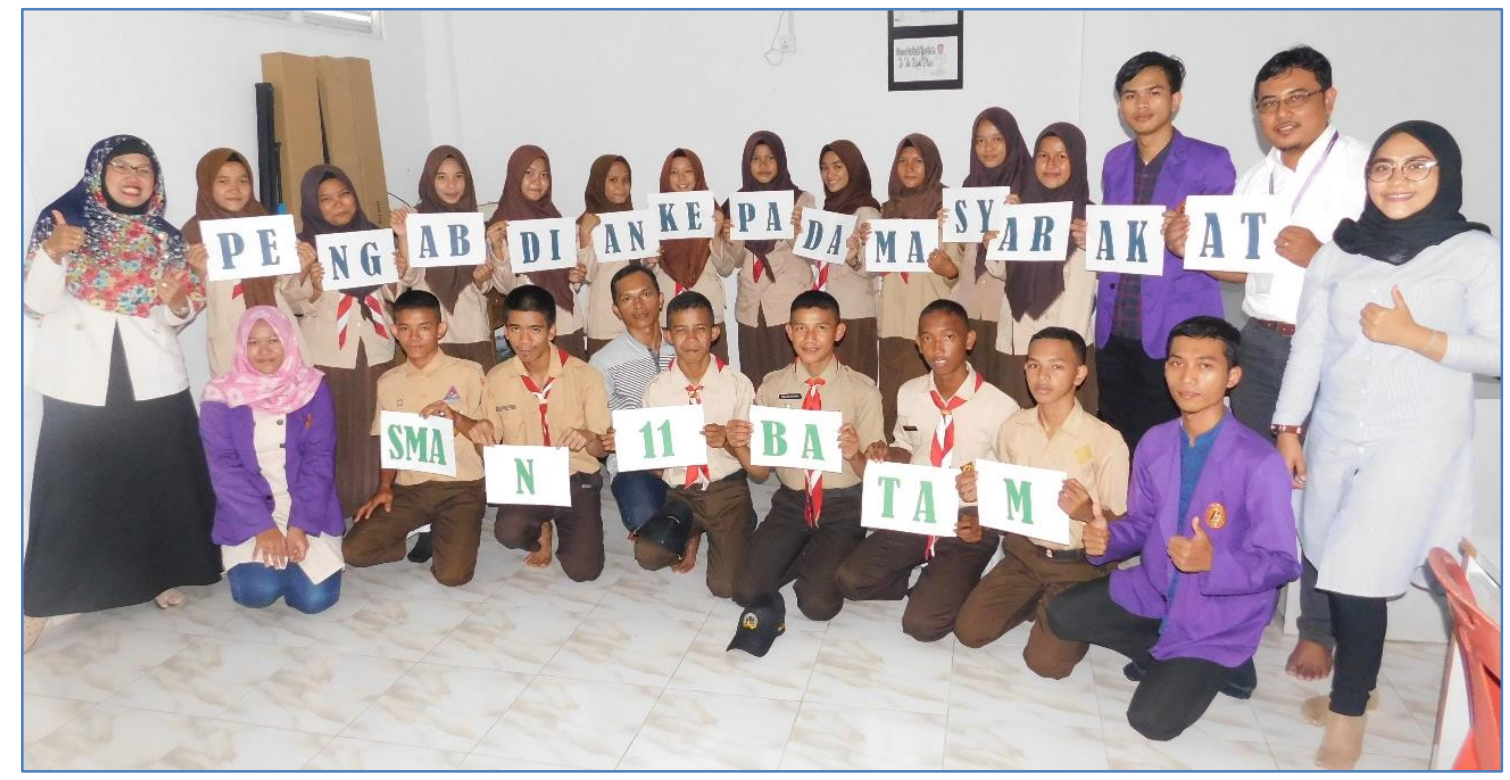

Gambar 2. Foto Dokumentasi Pengabdi Bersama Siswa dan Guru SMAN 11 Pulau Buluh Batam

\section{SIMPULAN}

Weblog adalah sarana paling mudah untuk berbagi informasi suatu organisasi. Weblog juga secara otomatis berhubungan dengan dapur proses pembuatan suatu berita ataupun artikel. Dengan pelatihan weblog bagi pengurus OSIS SMAN 11 Batam, maka segala kegiatan yang mereka lakukan dapat disebarkan dalam kanal weblog kepada siapa saja dan kapan saja. Melalui media weblog juga kreatifitas siswa dapat dimaksimalkan, misalnya bagaimana membuat berita yang menarik, membuat puisi, pantun atau cerita rakyat setempat.

Sementara itu bagi para guru SMAN 11 Pulau Buluh Batam yang mendapatkan pelatihan pemanfaatan media penyimpanan awan (cloud storage) mendapatkan metode baru bagaimana mengelola berkas-berkas penting, baik berkas pribadi maupun berkas sekolah pada media penyimpanan yang lebih aman, dapat diakses kapan saja dan dimana saja.

\section{DAFTAR RUJUKAN}

Goda, K., \& Kitsuregawa, M. (2012). The history of storage systems. Proceedings of the IEEE, 100 (SPL CONTENT), 1433-1440. 
Kurose, J. F., \& Ross, K. W. (2013). Computer Networking A Top-Down Approach. Pearson.

Noytim, U. (2010). Weblogs enhancing EFL students English language learning. Precedia Social and Behavioral Sciences, 2(December), 1127-1132.

Sultan, N. (2010). Cloud computing for education: A new dawn? International Journal of Information Management, 30(2), 109-116.

Ùimúek, Ö. (2010). The Effect of Weblog (blog) students' writing performance. Procedia Social and Behavioral Sciences, 2, 953-958. 